\title{
Detection and impacts of leakage from sub-seafloor deep geological Carbon Dioxide Storage
}

Jerry Blackford ${ }^{1 *^{+}}$, Henrik Stahl ${ }^{2+}$, Jonathan M. Bull ${ }^{3+}$, Benoît J.P. Bergès ${ }^{4}$, Melis Cevatoglu ${ }^{3}$, Anna Lichtschlag ${ }^{5}$, Douglas Connelly ${ }^{5}$, Rachael H. James ${ }^{3}$, Jun Kita ${ }^{6}$, Dave Long ${ }^{7}$, Mark Naylor ${ }^{8}$, Kiminori Shitashima ${ }^{9}$, Dave Smith ${ }^{7}$, Peter Taylor ${ }^{2}$, lan Wright ${ }^{5}$, Maxine Akhurst ${ }^{7}$, Baixin Chen ${ }^{10}$, Tom M. Gernon $^{3}$, Chris Hauton ${ }^{3}$, Masatoshi Hayashi ${ }^{11}$, Hideshi Kaieda ${ }^{12}$, Timothy G. Leighton ${ }^{4}$, Toru Sato ${ }^{13}$, Martin D.J. Sayer ${ }^{2,14}$, Masahiro Suzumura ${ }^{15}$, Karen Tait ${ }^{1}$, Mark E. Vardy ${ }^{3}$, Paul R. White ${ }^{4}$, Steve Widdicombe ${ }^{1}$

Blackford, J., Stahl, H., Bull, J.M. et al. 2014. Nature Climate Change, 4, 10111016 doi:10.1038/nclimate2381

${ }^{* 1}$ Plymouth Marine Laboratory, Prospect Place, Plymouth, PL1 3DH, UK.

${ }^{2}$ Scottish Association for Marine Science, Oban, Argyll, PA37 1QA, UK.

${ }^{3}$ Ocean and Earth Science, University of Southampton, National Oceanography Centre Southampton, Southampton, SO14 3ZH, UK.

${ }^{4}$ Institute of Sound and Vibration Research, Engineering and the Environment, University of Southampton, Highfield, Southampton, SO17 1BJ, UK

${ }^{5}$ National Oceanography Centre, University of Southampton Waterfront Campus, Southampton SO14 $3 \mathrm{ZH}, \mathrm{UK}$.

${ }^{6}$ Research Institute of Innovative Technology for the Earth, 9-2, Kizugawadai, Kizugawa-Shi, Kyoto, 619-0292 Japan.

${ }^{7}$ British Geological Survey, Murchison House, West Mains Road, Edinburgh, EH9 3LA, UK

${ }^{8}$ School of GeoSciences, Grant Institute, University of Edinburgh, Edinburgh EH9 3JW, UK.

${ }^{9}$ International Institute for Carbon-Neutral Energy Research, Kyushu University, 744 Motooka, Nishiku, Fukuoka 819-0395, Japan.

${ }^{10}$ School of Engineering \& Physical Sciences, Heriot-Watt University, Edinburgh, EH14 4AS, UK.

${ }^{11}$ The General Environmental Technos Co., Ltd., 1-3-5 Azuchimachi, Chuo-ku, Osaka 541-0052, Japan.

${ }^{12}$ CRIEPI, 1646 Abiko, Abiko-shi, Chiba 270-1194, Japan.

${ }^{13}$ Department of Ocean Technology, Policy and Environment, University of Tokyo. 5-1-5, Kashiwanoha, Kashiwa-shi, Chiba, 277-8561 Japan.

${ }^{14}$ NERC National Facility for Scientific Diving, Scottish Association for Marine Science, Oban, Argyll, PA37 1QA, UK.

${ }^{15}$ National Institute of Advanced Industrial Science and Technology, 16-1 Onogawa, Tsukuba, Ibaraki 305-8569, Japan.

${ }^{+}$These three authors contributed equally to this work

* Corresponding author

Jerry Blackford

Plymouth Marine Laboratory

Prospect place

Plymouth

PL1 3DH

UK

Email:jcb@pml.ac.uk

Tel: +44 (0)1752633468

Fax: +44 (0)1752 633101 
Fossil fuel power generation and other industrial emissions of carbon dioxide are a threat to global climate ${ }^{1}$, yet many economies will remain reliant on these technologies for several decades $^{2}$. Carbon dioxide Capture and Storage (CCS) in deep geological formations provides an effective option to remove these emissions from the climate system ${ }^{3}$. In many regions storage reservoirs are located offshore ${ }^{4,5}$, over a kilometre or more below societally important shelf seas ${ }^{6}$. Therefore concerns about the possibility of leakage ${ }^{7,8}$ and potential environmental impacts, along with economics, have contributed to delaying development of operational CCS. Here we investigate the detectability and environmental impact of leakage from a controlled sub-seabed release of $\mathrm{CO}_{2}$. We show that the biological impact and footprint of this small leak analogue $(<1$ tonne $\mathrm{CO}_{2} \mathrm{~d}^{-1}$ ) is confined to a few tens of metres. Migration of $\mathrm{CO}_{2}$ through the shallow seabed is influenced by near-surface sediment structure, and by dissolution and re-precipitation of calcium carbonate naturally present in sediments. Results reported here advance understanding of environmental sensitivity to leakage and identify appropriate monitoring strategies for full-scale carbon storage operations.

Geological carbon dioxide $\left(\mathrm{CO}_{2}\right)$ storage is proposed in deep, porous, sedimentary formations, 1-2 km below the seafloor, such as depleted oil and gas reservoirs or saline aquifers $\mathrm{s}^{3,4}$. Storage integrity is provided by impermeable layers of cap-rock ${ }^{3}$. Although debated, a number of mechanisms potentially facilitating leakage have been proposed, including abandoned exploratory bore-holes, geological discontinuities (e.g. fractures) and operational malfunction (blowout scenario) $)^{9}$. Here we do not address storage integrity, but focus on the likely environmental consequence of leakage, and how best to detect leakage if it were to reach the marine environment.

Research on excess $\mathrm{CO}_{2}$ in marine systems is frequently based on laboratory experiments and studies of natural $\mathrm{CO}_{2}$ seeps ${ }^{10,11}$. However, laboratory studies omit physical, ecological and behavioural complexity, which are key in understanding and regulating impacts. Further, volcanic $\mathrm{CO}_{2}$ seeps are compromised by impurities and atypical thermal, topographical and sedimentological properties ${ }^{12}$, and the initial evolution of $\mathrm{CO}_{2}$ flow is not known. Early detection of leakage that has reached the seabed from deep CCS storage formations is crucial for assurance, and monitoring must be viable in complex hydrodynamic environments. Consequently, we conducted a shallow controlled sub-seabed $\mathrm{CO}_{2}$ release in order to replicate small-scale, but realistic, leakage that has migrated into the near sea-bed environment. A borehole was drilled from shore, to a depth of $11 \mathrm{~m}$ beneath the seafloor, in $12 \mathrm{~m}$ of water and $350 \mathrm{~m}$ offshore (Supplementary Fig. 1). A total of 4.2 tonnes of $\mathrm{CO}_{2}$ were injected into the overlying unconsolidated sediments, over a 37 day period, during which flow was increased from 10 to $210 \mathrm{~kg} \mathrm{~d}^{-1}$. The temporal and spatial migration and impact of this $\mathrm{CO}_{2}$ release was assessed using a variety of acoustic, chemical and biological techniques, before, during and after release at both control and exposed sites. (See methods section, Supplementary Table 1). The experimental results are directly applicable to the majority of global offshore storage sites ${ }^{3}$, which are planned for shelf seas with water depths up to $200 \mathrm{~m} . \mathrm{CO}_{2}$ phase chemistry and benthic biogeochemical processes are consistent across this depth interval.

The physical movement of the injected $\mathrm{CO}_{2}$ through the seabed was clearly imaged (Fig. 1) . Within hours of commencing $\mathrm{CO}_{2}$ injection, small gas bubble plumes were observed at the seafloor. Seismic imaging of the sediments revealed a layered structure consisting of $8 \mathrm{~m}$ of fine laminated mud, overlain by $2 \mathrm{~m}$ of fine silty-sand with 1-2 $\mathrm{m}$ of coarse-grained sand and gravel forming the seabed (Fig. $1 \mathrm{a}$, inset). Repeated seismic reflection surveys showed that during the first 13 days of release, with $\mathrm{CO}_{2}$ injection between 10 and $80 \mathrm{~kg} \mathrm{~d}^{-1}$, most $\mathrm{CO}_{2}$ was confined to a vertical gas 'chimney' in the lower laminated mud, (Fig. 1a). Within these muds, fracture propagation, or reactivation of pre-existing fractures is inevitable and rapid once a critical pressure is exceeded. This is dependent on sediment cohesiveness, injection rate and cumulative gas flux ${ }^{13,14,15}$. Thus, chimneys are interpreted to represent a laterally restricted (i.e. 5-10 m wide) network of interconnected fractures (Fig. 1c). The change in grain size from mud to overlying silt and sand caused a step-change 
from a fracture-dominated flow regime to one dominated by capillary invasion ${ }^{15}$ and fluidisation with lower permeability. This is evidenced by the observed accumulation and lateral spread of gas at the top of the laminated mud layer (Fig. 1c, green outline). The absence of reflectance signals in the upper layers during early stages of the release is consistent with slow diffusion of gas. The initial flow of $\mathrm{CO}_{2}$ into the water column is restricted and thought to occur through pre-existent micro fractures, beyond the resolution of seismic imaging. The increased injection rate $\left(210 \mathrm{~kg} \mathrm{~d}^{-1}\right)$ applied during the second half of the experiment permits gas to fracture the silty sand layer (Fig. 1b), and permeate through the seabed's coarse-grained sand and gravels, consistent with chimneys extending from the injection point to the seafloor. Consequently sub-surface flow becomes more spatially focussed with time as the flow rate increases, (Fig. 1c, pink outline).

Rapid dissolution of gaseous $\mathrm{CO}_{2}$ into seawater significantly increases bottom water $\mathrm{CO}_{2}$ partial pressure close to the injection site, with values varying between 380-1500 $\mu$ atm, depending on the state of the tide and injection rate, compared to background values of 360-370 $\mu$ atm (Fig. $2 \mathrm{~b}$ ). The flux of gaseous $\mathrm{CO}_{2}$ across the seafloor was determined directly by divers collecting bubbles from each bubble stream, and estimated by acoustic inversion of hydrophone data ${ }^{16}$. On Day 33 direct measurements yielded an estimated total $\mathrm{CO}_{2}$ flow of $31.8 \mathrm{~kg} \mathrm{~d}^{-1}$ (Fig. $2 \mathrm{c}$ ). At this time the input into the system was $210 \mathrm{~kg} \mathrm{~d}^{-1}$, hence only $15 \%$ of total $\mathrm{CO}_{2}$ was being emitted in a gaseous phase across the sediment-water interface. Gaseous $\mathrm{CO}_{2}$ flow rates estimated from acoustic inversion (Fig. 2C,) varied significantly with tidally induced changes in hydrostatic pressure (Fig. 2a), agreeing well with observations from time-lapse photography and $\mathrm{pCO}_{2}$ data (Fig. 2b), and with flow determined by diver measurement. The 24 hour rolling average acoustically inferred gas flux responds consistently to the increased injection rate on Day 31 (Fig. 2c) and suggests that outgassing of $15 \%$ of the total injected $\mathrm{CO}_{2}$ was representative of the entire release phase.

The chemical response in the sediment pore waters was complex. $\mathrm{CO}_{2}$-induced chemical changes in the biotic upper $25 \mathrm{~cm}$ of pore waters were not observed until the last week of the $\mathrm{CO}_{2}$ injection period, and persisted for a maximum of two weeks after the release was stopped. During this period, dissolved inorganic carbon (DIC, dissolved $\mathrm{CO}_{2}$ and associated inorganic carbon species) increased by a factor of ten from typical values of $2.6 \mathrm{mmol} \mathrm{kg}^{-1}$ to $29.3 \mathrm{mmol} \mathrm{kg}{ }^{-1}$ approximately 20 $\mathrm{cm}$ below the sediment surface (Fig. 3a). Coincident increased concentrations of pore water alkalinity and calcium ions $\left(\mathrm{Ca}^{2+}\right)$ (Fig. $3 \mathrm{~b}-\mathrm{c}$ ) indicate that the injected $\mathrm{CO}_{2}$ that dissolves promotes rapid dissolution of calcium carbonate $\left(\mathrm{CaCO}_{3}\right)$, naturally present in the sediments. In corroboration of this, pore water acidity $(\mathrm{pH})$ initially drops slightly from 7.7 to 7.5 , and then increases to 7.8 just after the injection was stopped (Fig. 3e), indicating that the rise in DIC was buffered by the carbonate dissolution. Carbon isotopic composition of pore water DIC at the release epicentre $\left(\delta^{13} C_{D I C}=\sim-20 \%\right.$ ) was significantly lower than background pore water $(\sim-2 \%)$, which confirms that changes in pore water carbonate chemistry were caused by the injected $\mathrm{CO}_{2}\left(\delta^{13} \mathrm{C}=-26.6 \%\right.$, Fig. $\left.3 \mathrm{~d}\right)$. All pore water carbonate chemistry parameters, including $\delta^{13} \mathrm{C}_{\mathrm{DIC}}$, returned to background values within 17 days of ceasing the $\mathrm{CO}_{2}$ injection, likely due to a combination of re-precipitation ${ }^{17}$ of $\mathrm{CaCO}_{3}$, physical and biological pore water advection ${ }^{18,19}$ or sinking of slightly dense $\mathrm{CO}_{2}$-rich pore water ${ }^{20}$.

Although changes in concentrations of pore water $\mathrm{DIC}$ and $\mathrm{Ca}^{2+}$ in response to $\mathrm{CO}_{2}$ were observed from 2-25 cm-depth in the sediments, concentrations remained near background values in the top 2 centimetres of sediment throughout the experiment (Fig. 3a, c) and benthic chamber measurements of DIC fluxes across the seafloor showed no change from normal values ${ }^{21}$ (Supplementary Fig. 2). Hence we conclude that the portion of injected $\mathrm{CO}_{2}$ that does not escape from the sediments in the gas phase (i.e. $85 \%$ ) was retained within the sediments for the duration of the experiment. Although some of this was observable as free-gas via acoustic imaging (Fig. 1), the high solubility of $\mathrm{CO}_{2}$ would suggest that much of the injected gas was rapidly dissolved in 
sediment pore waters.

As high $\mathrm{CO}_{2}$ is known to impact many biological processes ${ }^{22}$ we investigated the degree to which chemical changes from leakage might impact biological systems, in and around the seabed. Seabed communities naturally change, sometimes significantly, throughout the seasonal cycle (Fig. 4 , black lines). Impact is indicated not by change per se, but by deviations from well-established normal cycles. No biological effect was detected during the initial stages of the release, consistent with the lack of a chemical signal in the superficial sediments. However, towards the end of the release and in the initial days of the recovery period, the change in benthic macrofauna community structure at the leak epicentre (Fig. 4, red lines) was significantly different to that observed at the other, un-impacted sites. Intermittently the high $\mathrm{CO}_{2}$ plume in the water column was advected $25 \mathrm{~m}$ from the epicentre due to tidal circulation, inducing transitory changes in carbonate chemistry. Here bacterial gene expression in the top $1 \mathrm{~cm}$ of sediment responded similarly to that at the leakage epicentre (Supplementary Fig. 3 ), indicating a rapid sensitivity of the active bacterial community. No other $\mathrm{CO}_{2}$ impact was recorded away from the release epicentre at any stage. The dominant biological variability at both release and control sites was the normal seasonal dynamic, at the end of the sampling period no significant difference between impacted and non-impacted communities was apparent in the macrofauna (Fig. 4c), although differences in the gene expression of microbial populations persisted for at least 90 days (Supplementary Fig. 3).

Our work demonstrates that biological effects from a small short term leak are detectable, but not catastrophic and that recovery is measurable in days to weeks. The restricted vertical and horizontal effect of our small-scale leak is not without parallel. The effects of natural seepage of methane into the water column from cold seeps such as pockmarks and mud volcanoes on continental margins is restricted to a narrow zone that only extends a few metres from the seep epicentre ${ }^{23,24}$. The distribution of bacterial communities and macrofauna at these seeps is principally controlled by the rate of fluid flow ${ }^{25,26}$, and the bacterial communities respond rapidly to changes in environmental conditions ${ }^{27}$.

We caution that impacts are likely to increase step-wise if a greater proportion of $\mathrm{CO}_{2}$ is emitted in the gaseous phase, either through fractures or as pore waters become super-saturated, or if the carbonate buffering capacity of the sediments is limited or becomes exhausted. Without operational evidence, realistic leakage scenarios can only be approximated. Based on natural gas seepage and offshore drilling, estimates range from $\sim 20$ tonnes per annum (half the experimental release rate) for seepage via abandoned wells to short-term leakage of 50 kilotonnes per day for highly unlikely blowout scenarios ${ }^{9}$. Modelling derived estimates of the footprint of biologically harmful plumes of $\mathrm{CO}_{2}$ indicate that high end scenarios may impact a few kilometres radius ${ }^{28}$ whilst lower end scenarios, consistent with this experiment, will impact only some metres in radius ${ }^{29}$. For all leakage scenarios so far examined, models indicate that hydrodynamic mixing would disperse harmful concentrations of $\mathrm{CO}_{2}$ within hours to weeks, facilitating recovery as excess $\mathrm{CO}_{2}$ is not accumulated in biological tissues unlike most toxic substances. Siting storage below restricted exchange environments, where dispersion is limited, could lead to significant build-up of $\mathrm{CO}_{2}$ charged water ${ }^{12}$ and should be avoided.

Monitoring the large volume of seawater overlying a geological storage complex will be challenging. We show that low levels of leakage dominated by dissolution and subsequent transport of $\mathrm{CO}_{2}$ by diffusion may be hard to detect and quantify, due to carbonate buffering. Small seabed pockmarks are an early indication of leakage, but these features can be difficult to distinguish from natural biogenic structures. Bubble streams, when present, are easily recorded, but we observed that these are sensitive to hydrostatic pressure and may represent a fraction of released $\mathrm{CO}_{2}$. Although seismic and chemical signals over an established leakage locus will be distinct, given the restricted horizontal and vertical footprint of leakage, spatial coverage and the ability to measure 
signals near the seabed will be paramount for monitoring. Furthermore, natural biologically and physically driven variability of $\mathrm{CO}_{2}$ in marine systems ${ }^{30}$ and sediment heterogeneity may render detection of signals at small distances from leakage loci hard to discriminate, unless a rigorous baseline is established.

We suggest that the optimal monitoring strategy for storage locations should use mobile autonomous underwater vehicles equipped with chemical (for dissolved phase) and acoustic (for gas bubbles) sensors with a horizontal spatial sampling resolution approaching 10 metres, deployed close to the seafloor. Such a multi-sensor approach, supported by analysis against a well constrained baseline will maximise the chance of detecting the preliminary stages of a small leakage. Should specific higher risk, spatially restricted, leakage sites be identified, a network of permanently deployed long-term stable online sensors and hydrophones may provide the most effective monitoring tools for early leak detection. Once a suspected leak is detected, alternative techniques should be implemented to corroborate the source (e.g. by sensors and isotopic signature); to quantify fluxes of $\mathrm{CO}_{2}$ (e.g. by acoustic inversion for gas and sediment-pore water incubations for dissolved phase) and to assess associated impacts (e.g. by biological sampling). Baseline studies therefore need to encompass sediment structure and carbonate content, natural seeps, the acoustic background, $\mathrm{CO}_{2}$ chemistry and biological community structure within the context of seasonal and spatial heterogeneity.

We do not address the robustness of deep geological storage in this work, but provide an insight into the processes that occur if leaked $\mathrm{CO}_{2}$ were to reach the shallow unconsolidated sediments immediately underlying the seabed. This emerging understanding synthesising dispersion, impact and recovery suggests that small scale leakage from CCS, should it reach the seafloor, is highly unlikely to have a regionally significant environmental impact. Whilst monitoring may be challenging, it is tractable given a multivariate approach, supported by appropriate baseline studies.

\section{References}

1. IPCC (2001) The Third assessment report of the Intergovernmental Panel on Climate Change (IPCC). Cambridge University Press: Cambridge, UK and New York, USA.

2. Raupach, M.R., Marland, G., Ciais, P., Le Quéré , C., Canadell , J.G., Klepper , G., \& Field, C.B. Global and regional drivers of accelerating $\mathrm{CO}_{2}$ emissions PNAS 104, 10288-10293 (2007).

3. IPCC, 2005: IPCC Special Report on Carbon Dioxide Capture and Storage. Prepared by Working Group III of the Intergovernmental Panel on Climate Change [Metz, B., O. Davidson, H. C. de Coninck, M. Loos, and L. A. Meyer (Eds.)]. Cambridge University Press, Cambridge, United Kingdom and New York, NY, USA, $442 \mathrm{pp}$.

4. Senior, B. $\mathrm{CO}_{2}$ Storage in the UK - Industry Potential, DECC, URN 10D/512, 2010.

5. Nakanishi, S. et al. Methodology of $\mathrm{CO}_{2}$ aquifer storage capacity assessment in Japan and overview of the project. Energy Procedia 1, 2639-2646 (2009).

6. Austen, M. C. et al. Marine. In: The UK National Ecosystem Assessment Technical Report (UK NEA, 2011). Publishers: UNEP-WCMC 2011.

7. Van Noorden, R, Carbon sequestration: Buried trouble Nature 463, 871-873 (2010).

8. Monastersky, R. Seabed scars raise questions over carbon-storage plan. Nature 504, 339-340

(2013).

9. IEA Greenhouse Gas R\&D programme (IEA GHG) Assessment of Sub-sea ecosystem impacts. (2008).

10. Widdicombe, S., Blackford, J. C. \& Spicer, J. I. Assessing the environmental consequences of $\mathrm{CO}_{2}$ leakage from geological CCS: Generating evidence to support environmental risk assessment. Mar. Pollut. Bull. 73, 399-401 (2013).

11. Caramanna, G., Voltattorni, N. \& Maroto-Valer, M. Is Panarea Island (Italy) a valid and costeffective natural laboratory for the development of detection and monitoring techniques for submarine $\mathrm{CO}_{2}$ seepage? Greenhouse Gases: Science and Technology 1, 200-210, (2011). 
12. Carey, S. et al. $\mathrm{CO}_{2}$ degassing from hydrothermal vents at Kolumbo submarine volcano, Greece, and the accumulation of acidic crater water. Geology 41, 1035-1038, (2013).

13. Boudreau, B. P. et al. Bubble growth and rise in soft sediments. Geology 33, 517-520 (2005). 14. Algar, C. K., Boudreau, B. P. \& Barry, M. A. Initial rise of bubbles in cohesive sediments by a process of viscoelastic fracture. J. Geophys. Res. 116, B04207 (2011).

15. Jain, A. K. \& Juanes, R. Preferential mode of gas invasion in sediments: Grain-scale mechanistic model of coupled multiphase fluid flow and sediment mechanics. J. Geophys. Res. 114, B08101 (2009).

16. Leighton, T. G. \& White, P. R. Quantification of undersea gas leaks from carbon capture and storage facilities, from pipelines and from methane seeps, by their acoustic emissions, Proc. R. Soc. a-Mathematical Phys. Eng. Sci. 468, 485-510 (2012).

17. Mucci, A. et al. Fate of carbon in continental shelf sediments of eastern Canada: a case study. Deep-Sea Res. I/ 47, 733-760 (2000).

18. Aller, R. C. \& Aller, J. Y. The effect of biogenic irrigation intensity and solute exchange on diagenetic reaction rates in marine sediments. J. Mar. Res. 56, 905-936 1998.

19. Janssen, F., Huettel, M. \& Witte, U., Pore-water advection and solute fluxes in permeable marine sediments (II): Benthic respiration at three sandy sites with different permeabilities (German Bight, North Sea). Limnol. Oceanogr. 50, 779-792 2005.

20. Duan, Z., Hu, J., Li, D. \& Mao, S. Densities of the $\mathrm{CO}_{2}-\mathrm{H}_{2} \mathrm{O}$ and $\mathrm{CO}_{2}-\mathrm{H}_{2} \mathrm{O}-\mathrm{NaCl}$ systems up to $647 \mathrm{~K}$ and 100 MPa. Energ. \& Fuel. 22, 1666-1674 (2008).

21. Anderson, L.G. et al. Benthic respiration measured by total carbonate production. Limnol. Oceanogr. 31, 319-329 (1986)

22. Gattuso, J.P. \& Hansson, L., (Eds.), Ocean Acidification. Oxford University Press, 326 pages, (2011).

23. DeBeer $D$, et al. In situ fluxes and zonation of microbial activity in surface sediments of the Håkon Mosby mud volcano. Limnol. Oceanogr. 51, 1315-1331. (2006).

24. Lichtschlag, A. et al. Methane and sulfide fluxes in permanent anoxia: In situ studies at the Dvurechenskii mud volcano (Sorokin Trough, Black Sea), Geochim. Cosmochim. Ac. 74, 5002-5018, (2010).

25. Decker, C. et al. Habitat heterogeneity influences cold-seep macrofaunal communities within and among seeps along the Norwegian margin. Part 1: macrofaunal community structure. Marine Ecology 33, 205-230, (2012).

26. Gruenke, S. et al. Niche differentiation among mat-forming, sulfide-oxidizing bacteria at cold seeps of the Nile Deep Sea Fan (Eastern Mediterranean Sea). Geobiology 9, 330-348, (2011).

27. Felden, J. et al. Limitations of microbial hydrocarbon degradation at the Amon mud volcano (Nile deep-sea fan), Biogeosciences 10, 3269-3283, (2013).

28. Blackford, J.C., Jones, N., Proctor, R. \& Holt, J. Regional scale impacts of distinct $\mathrm{CO}_{2}$ additions in the North Sea, Mar. Poll. Bull. 56, 1461-1468, (2008).

29. Dewar, M., Wei, W., McNeil, D. \& Chen, B. Small scale modelling of the physiochemical impacts of $\mathrm{CO} 2$ leaked from sub-seabed reservoirs or pipelines within the North Sea and surrounding waters. Mar. Prod. Bull. 73, 504-515, (2013).

30. Thomas, H., Bozec, Y., Elkalay, K., de Baar, H.J.W., Borges, A.V. \& Schiettecatte, L.-S. Controls of the surface water partial pressure of $\mathrm{CO}_{2}$ in the North Sea. Biogeosciences 2, 323-334, (2005).

31. Shitashima, K., Kyo, M., Koike, Y., \& Henmi, H. Development of in-situ pH sensor using ISFET. Proceedings of the 2002 International Symposium on Underwater Technology. IEEE/02EX556, 106108. (2002).

32. Clarke, K.R. Non-parametric multivariate analyses of changes in community structure. Aust. J. Ecol. 18, 117- 143, (1993).

33. Kruskal, J.B., Wish, M. Multidimensional Scaling. Sage Publications, Beverly Hills, CA (1978). 


\section{Methods}

The experiment site, located on the west coast of Scotland (Supplementary Fig. 1, inset), fulfilled multiple criteria including access and logistics, regulatory release permissions, local approval, suitable seabed geology and sediments with diverse fauna typical of regional shelf seas. Extensive high-resolution seismic reflection profiling and sediment core sampling were instrumental in site selection and subsequently fully characterized the site for drilling operations. A 350 metrelong borehole, subsequently lined with stainless steel pipe was drilled through quartzite bedrock using a directional drilling rig, avoiding glacial till deposits and natural accumulations of biogenic gas, with the final ten metres terminating horizontally into unconsolidated sediments (Supplementary Fig. 1). The borehole terminated in a five metre long diffuser with multiple perforations of $0.5 \mathrm{~mm}$ diameter, to ensure diffuse flow of gas into the surrounding sediments. The diffuser was positioned $11 \mathrm{~m}$ below the seabed and beneath a further 10 to 12 metres of water, dependent on tide height. The land-based facilities comprised $\mathrm{CO}_{2}$ cylinders; connected by manifolds, regulated by a highprecision mass-flow controller, logging at 12 second periodicity. Initial injection was commenced at $10 \mathrm{~kg} \mathrm{CO}_{2} \mathrm{~d}^{-1}$ to avoid hydraulic fracturing, increasing to $210 \mathrm{~kg} \mathrm{CO}_{2} \mathrm{~d}^{-1}$ to achieve a realistic flux and biogeochemically significant signal at the seabed. The total injection amounted to 4.2 tonnes over a 37 day period.

Surveying used a combination of boat-towed instrumentation; diver-mediated sampling and semi-permanently deployed instrumentation on the sea floor. Sampling was undertaken at four bathymetrically and ecologically similar zones (Zone 1: Epicentre, Zone 2: $25 \mathrm{~m}$ distant, Zone 3: $75 \mathrm{~m}$ distant, Zone 4: $450 \mathrm{~m}$ distant acting as a control, Supplementary Fig. 1). The sites were investigated immediately prior to the start of $\mathrm{CO}_{2}$ release; during the 37 day release period; and over one year after termination of the release (Supplementary Table 1).

High-resolution seismic reflection data comprised 194 Boomer and Chirp profiles, covering an area of 600 by 400 metres centered above the diffuser location, with a 5-10 metre line separation. A calibrated hydrophone was deployed close to the diffuser to record the acoustic signature of gas bubbles emitted from the seabed within the water column.

$\mathrm{CO}_{2}$ fluxes across the sediment-water interface were quantified by direct diver collection, a passive acoustic inversion technique ${ }^{16}$ based on hydrophone data and benthic chambers for quantifying dissolved inorganic carbon (DIC) flux. The partial pressure of $\mathrm{CO}_{2}$ in the water column was monitored by a calibrated $\mathrm{pCO}_{2}$ ISFET electrode ${ }^{31}$ moored at five centimetre height above the seabed at the centre of the release site.

Sediment samples for pore water biogeochemistry analysis, including DIC, total alkalinity (TA), $\mathrm{pH}$, isotopic composition $\left(\delta^{13} \mathrm{C}_{\mathrm{DIC}}\right), \mathrm{Ca}^{2+}$ and biological samples, were manually collected in shallow cores by divers. At each Zone and time-point five replicate cores were analysed for microbial, and macro-faunal populations. Fauna were analysed to the lowest taxonomic level possible. Microbial RNA was extracted and analysed using terminal restriction fragment length polymorphism; a molecular biology technique commonly used to profile microbial communities, based on the position of a restriction site closest to a labeled end of the 16S rRNA gene.

This study uses a nonparametric multivariate approach, multi-dimensional scaling (MDS) which characterises and compares faunal samples based on the identity and abundance of macrofaunal species (Fig. 4) or microbial 16S rRNA gene T-RF (terminal restriction fragment) relative abundances (Supplementary fig. 3). Ordinations are derived from Bray Curtis similarity matrices using a MDS technique ${ }^{32,33}$. The Bray-Curtis measure ignores joint absences and focuses on presences and is the most commonly used similarity matrix for biological community analyses. An MDS ordination is essentially a map of samples in which the distance between any two samples is a reflection of their relative similarity to each other based on the whole community composition. 
Thus, samples positioned closely to each other are very similar in community composition, and points that are further apart are less similar in their composition. The goodness of fit of the ordination (given that a multi-dimensional distribution is compressed to a two-dimensional one) is indicated by a stress value. Values below $0.2 \mathrm{imply}$ that the ordinations may be sensibly interpreted. As this technique is based on the rank order in the similarity matrix, it is only the relative distance apart of the symbols that matters, the scale and axis being arbitrary.

An animation of the experimental procedure and video footage of seafloor bubble streams and instrumentation can be seen at www.qics.co.uk. Supplementary Table 1 summarises the sampling regime and further details are given in the supplementary text.

All correspondence and requests for materials should be addressed to J Blackford (jcb@pml.ac.uk).

Acknowledgements Funding was provided by NERC (NE/H013962/1), the Scottish Government and METI/MEXT of Japan. We thank the Tralee Bay Holiday Park, Lochnell Estates and the inhabitants of Benderloch for hosting the experiment. We acknowledge Marine Scotland and The Crown Estate for permissions to carry out the research. The NERC National Facility for Scientific Diving, the crew of the R. V. Seol Mara and John Montgomery based at SAMS provided operational support. We thank Alister Skinner of ACS coring services for advice on the drilling, and the design of the well screen; John Davis for support of geophysical data acquisition; Craig Wallace of Kongsberg Ltd for provision and processing of the multibeam bathymetry data; Joana Gafiera (BGS) for interpretation of site survey seismic profiles and Alison Monaghan (BGS) for construction of 3D geological models.

Author Contributions R.J., D.C., H.S., S.W., K.S., A.L., P.T., J.K., C.H., K.T., M.S. and M.H. designed and undertook biogeochemical measurements and analysed data; M.C., M.V., I.W., D.L., D.S., J.M.B., and M.A. planned, acquired and interpreted seismic reflection data; T.L., P.W. and B.B. designed and undertook passive acoustic measurements, analysed data and completed gas flux inversion; T.M.G. analysed and interpreted core data; B.C. analysed bubble dynamics from bottom photographs; M.D.J.S. led the diving deployment and sampling strategy; B.C., H.K. and T.S. developed models to constrain the experimental deployment; D.L., D.S. and M.A. developed concept, design and implementation of borehole and gas delivery mechanism; H.S., P.T. and M.N. designed and built the $\mathrm{CO}_{2}$ injection facility; H.S. led and coordinated the release and sampling strategy; J.B., H.S., I.W., R.J., J. K., B.C., C.H., S.W. and M.N. conceived the study ; J.B. led the project; D.S., B.B., M.C. and A.L. produced figures within the manuscript; J.B., H.S. and J.M.B. developed and co-wrote the manuscript. All authors discussed results and commented on the manuscript.

CFI Statement: The authors declare no competing financial interests. 


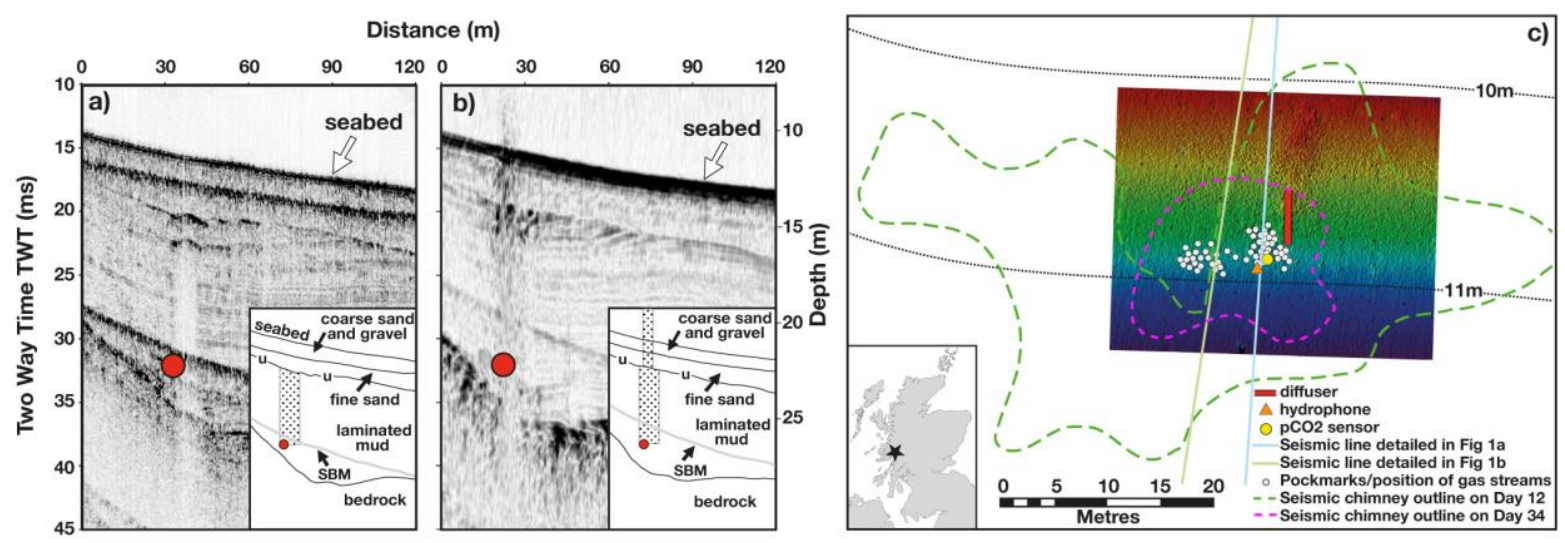

Figure 1. Seismic reflection profiles and seabed mapping illustrating gas pathways above the $\mathrm{CO}_{2}$ diffuser. The position of the diffuser $11 \mathrm{~m}$ beneath the seabed is indicated by the red dots and red line. Insets show line drawing interpretations. The Sea Bed Multiple (SBM) is an artefact. a) Day 13. The data images a bright spot beneath the fine sand layer. This is interpreted as free gas being trapped beneath the unconformity (U), and no gas is imaged in the water column. b) Day 34 . Enhanced reflectivity above the diffuser, and acoustic turbidity from the diffuser to the seabed and into the water column are interpreted as free gas. c) Plan view multibeam image of $\mathrm{CO}_{2}$ leakage at the seabed on Day 34. Gas emitting pockmarks (white circles) sit within the area of the chimneys imaged by seismic reflection data on day 13 (green dashes) and day 34 (pink dashes). The sub-surface flow became more spatially focussed with time as the flow rates were increased. The locations of the hydrophone (orange triangle) and $\mathrm{pCO}_{2}$ instruments (yellow circle, data shown in Fig. 2) are indicated. (See also Supplementary Fig. 1). 


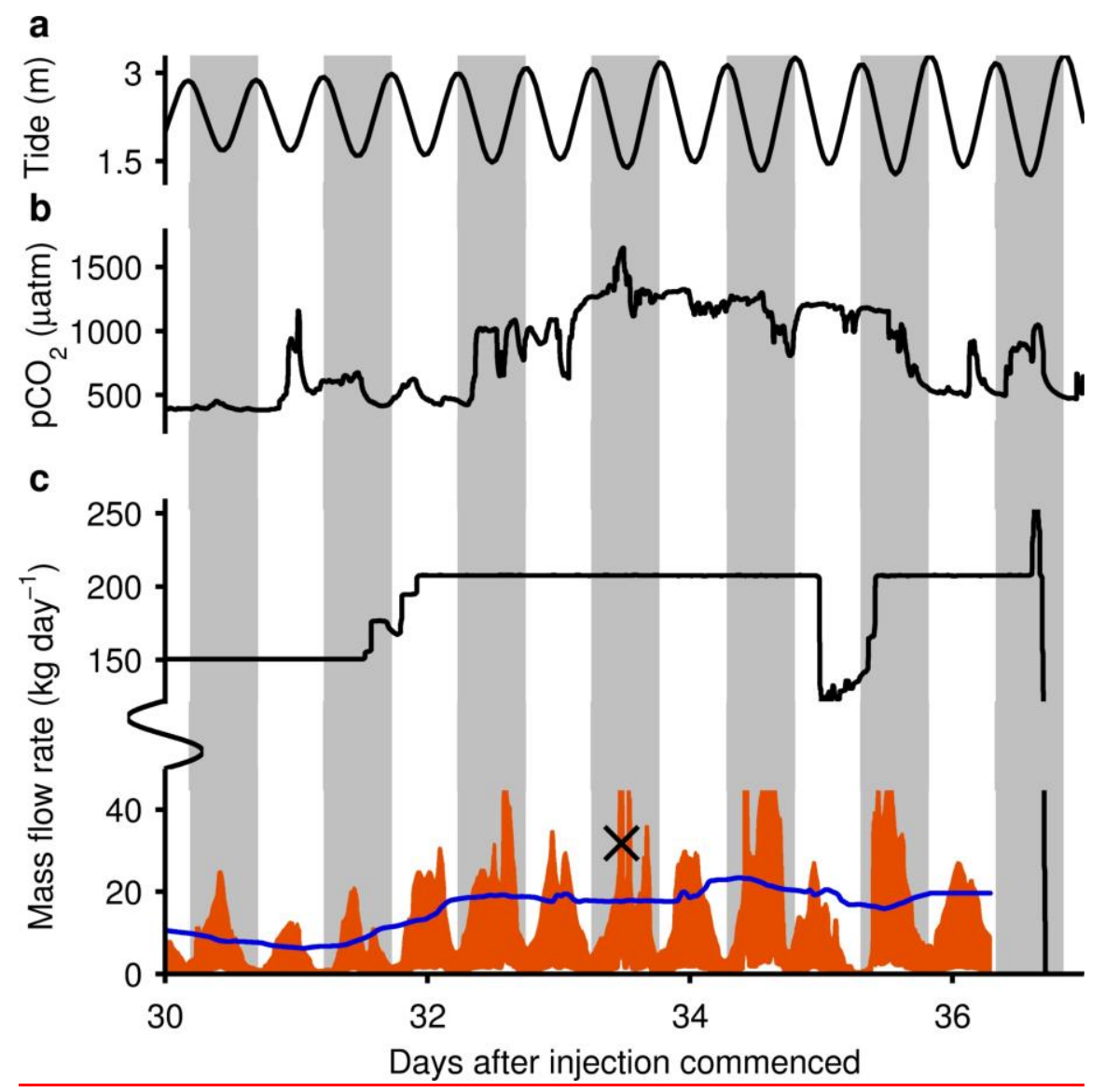

Figure 2. Gas injection rate, hydrophone-determined seabed flux, and carbonate system variations in the water column over multiple tidal cycles during the later stages of injection. $\mathrm{pCO}_{2}$ and seabed gas flux correlates with the tidal cycle, with low gas flux at high-tide. a) height of tidal cycle in metres b) Variation in $\mathrm{pCO}_{2}$ ( $\left.\mu \mathrm{atm}\right) 5 \mathrm{~cm}$ above the seabed c) total gas injection flux ( $\mathrm{kg} \mathrm{day}^{-1}$, solid black line), estimate of gas flux at the seabed from inversion of hydrophone data (orange area $25^{\text {th }}$ and $75^{\text {th }}$ percentiles of confidence interval; 24-hour rolling mean - solid blue line). See supplementary material for details on the inversion. Direct diver measurement of gas flux on Day 33 (between 11:00 and 11:49) is shown by the black cross. Data is illustrated for the period between Day 30 and Day 36 of the release. 

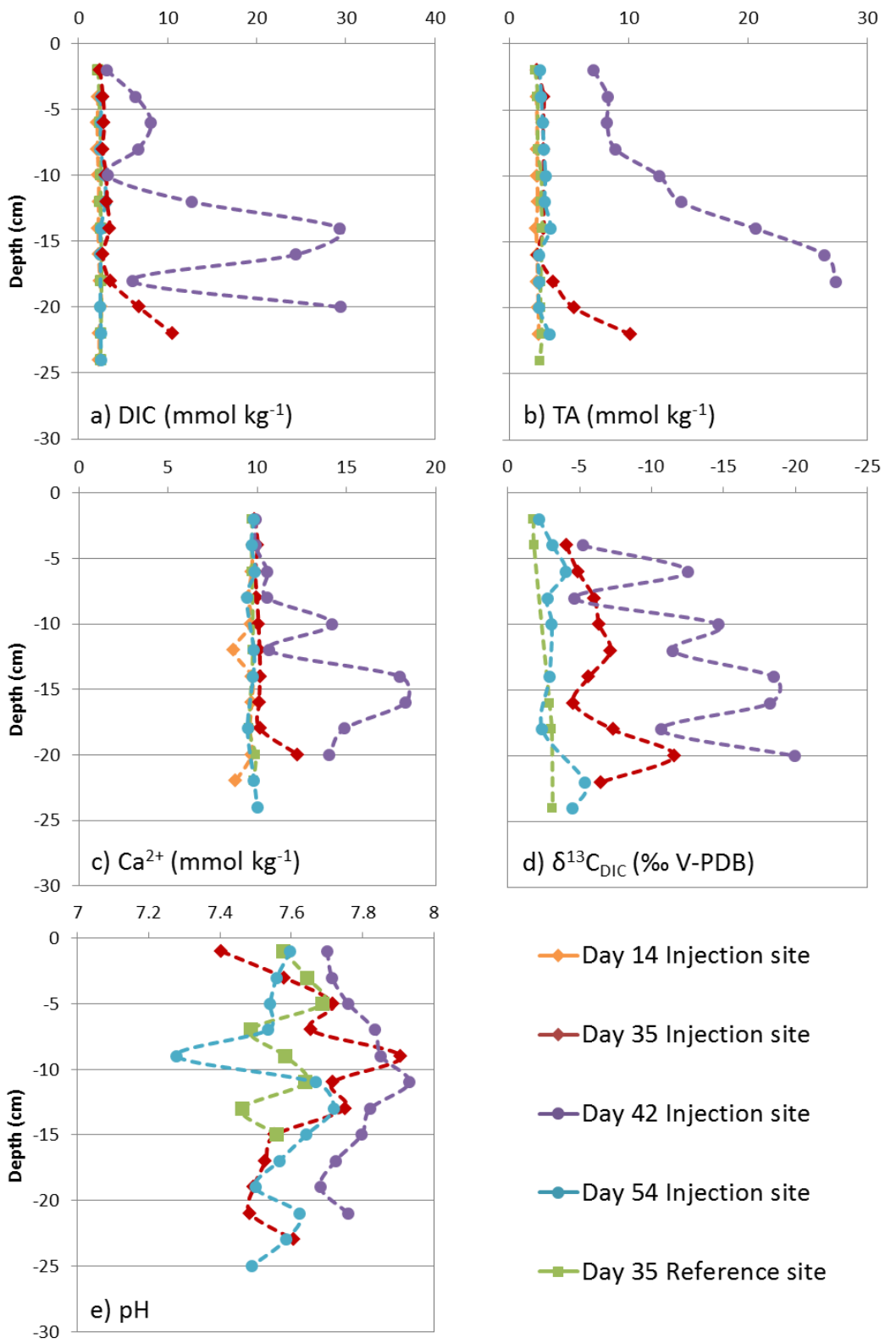

Figure 3. Temporal evolution of dissolved carbonate system parameters in sediment pore water at the injection site (zone 1). Data are shown for Day 14 and Day 35 during the injection phase and at 5 days and 17 days after the gas release ceased (Day 42 and Day 54 of the experiment respectively). A typical profile from the control site (Zone 4, Day 35, green line) is also shown for comparison. a) Dissolved Inorganic Carbon (DIC, $\left.\mathrm{mmol} \mathrm{kg}{ }^{-1}\right)$; b) Total Alkalinity (TA, mmol kg$\left.{ }^{-1}\right)$; c) Calcium $\left(\mathrm{Ca}^{2+}, \mathrm{mmol} \mathrm{kg}^{-1}\right)$; d) Carbon isotopic composition of $\mathrm{DIC}\left(\delta^{13} \mathrm{C}_{\mathrm{DIC}} \%\right.$ \% V-PDB) and e) pH. Deviations from control values (green) are only apparent on days 35 and 42. $\delta^{13}$, 

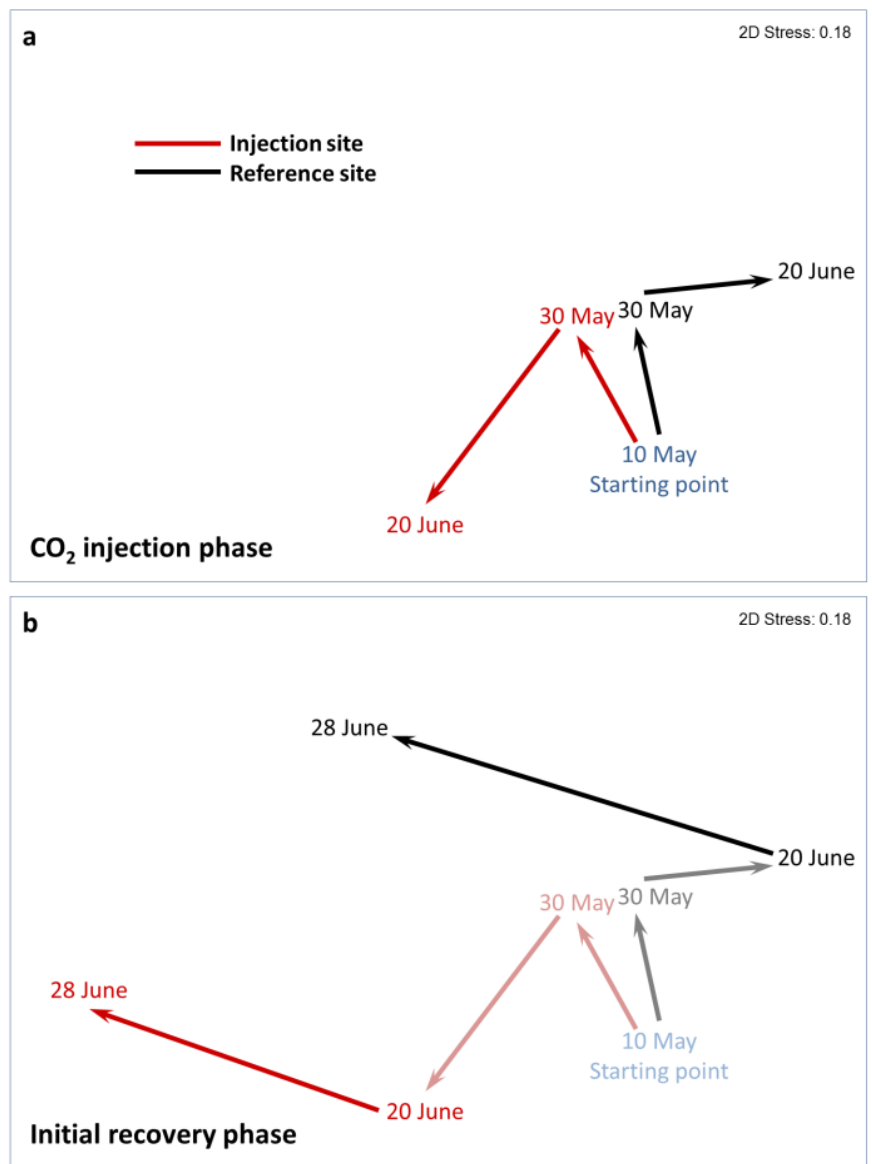

C

2D Stress: 0.18

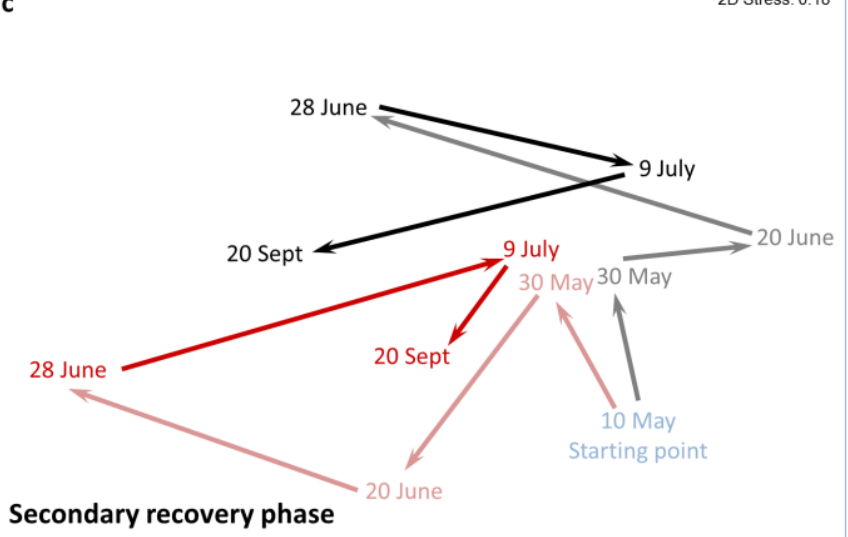

Figure 4. Plot comparing temporal changes in benthic macrofaunal community structure at the release site with the reference sites.

In a multi-dimensional scaling (MDS) plot, similar biological communities in terms of biodiversity and abundance (represented by dates) appear close together and parallel trajectories (arrows) represent comparable changes. Dissimilarity is represented by greater spatial separation or diverse trajectories. a) During the initial stages of leakage, until 30-May community development is similar at both impacted and reference sites, however in the later stages of the injection, significant divergence is apparent. b) During the initial stages of recovery, until 28-June both impacted and non-impacted communities show similar trajectories, but remain dissimilar in make-up. c) In the later stages of recovery convergence between all communities is apparent. The generation of MDS plots is detailed further in the methods section, the reference data represents an average of the three separate non-impacted sites. 